\title{
Recombinant human erythropoietin therapy after allogeneic hematopoietic cell transplantation with a nonmyeloablative conditioning regimen: Low donor chimerism predicts for poor response

\author{
Gaëtan Vanstraelen*, Frédéric Baron*, Evelyne Willems, Christophe Bonnet, Kaoutar Hafraoui, \\ Pascale Frère, Georges Fillet, and Yves Beguin \\ Department of Medicine, Division of Hematology; University of Liege, Liege, Belgium
}

(Received 3 November 2005; revised 12 April 2006; accepted 13 April 2006)

\begin{abstract}
Purpose. After allogeneic hematopoietic stem cell transplantation with nonmyeloablative conditioning (NMHCT), many patients experience prolonged anemia and require red blood cell (RBC) transfusions. We enrolled 60 consecutive patients undergoing NMHCT in a phase II trial to determine the optimal utilization of recombinant human erythropoietin (rHuEPO) therapy in this setting.

Patients and Methods. The first 14 NMHCT recipients did not receive rHuEPO (control group). Nineteen patients were scheduled to start rHuEPO on day 0 (EPO group 2) and 27 patients on day 28 after the transplant (EPO group 1). RHuEPO was administered subcutaneously once weekly at a dose of $500 \mathrm{U} / \mathrm{kg} / \mathrm{wk}$ with the aim of achieving hemoglobin (Hb) levels of $13 \mathrm{~g} / \mathrm{dL}$. The 3 groups were well balanced for major characteristics.

Results. During the first month $(p<0.0001)$ as well as days 30 to $100(p<0.0001)$ and days 100 to $180(p<0.0001)$, Hb values were higher in patients receiving rHuEPO compared to those not receiving it. However, transfusion requirements were significantly decreased only in the first month in EPO group $2(p=0.0169)$. T-cell chimerism above $60 \%$ on day 42 was the best predictor of $\mathrm{Hb}$ response $(p<0.0001)$ or $\mathrm{Hb}$ correction $(p=0.0217)$, but myeloid chimerism above $90 \%$ also predicted for $\mathrm{Hb}$ response $(p=0.0069)$. Hb response was also decreased in patients receiving CD8-depleted grafts and increased in the few patients not receiving TBI, but only in univariate analysis.

Conclusions. Anemia after NMHCT is sensitive to rHuEPO therapy, but less so than after conventional allogeneic HCT. RHuEPO decreases transfusion requirements only in the first 30 days posttransplant. T-cell chimerism below $60 \%$ on day 42 impaired $\mathrm{Hb}$ response, suggesting possible inhibition of donor erythropoiesis by residual recipient lymphocytes. A prospective randomized trial should be performed with rHuEPO starting on the day of transplantation to assess its clinical benefit in terms of transfusion requirements and quality of life. (c) 2006 International Society for Experimental Hematology. Published by Elsevier Inc.
\end{abstract}

Allogeneic hematopoietic cell transplantation (HCT) is increasingly used in selected patients with hematological malignancies [1]. Its curative potential is in part achieved through an immune-mediated destruction of malignant cells by donor lymphocytes termed the graft-vs-leukemia (GVL)

Offprint requests to: Yves Beguin, M.D., University of Liege, Department of Hematology, CHU Sart Tilman, 4000 Liege, Belgium; E-mail: yves.beguin@chu.ulg.ac.be

*The two first authors contributed equally to this work. effect [2]. However, because of its toxicity, conventional allogeneic HCT is restricted to younger and fitter patients [1]. Therefore, several groups have developed the concept of reduced-intensity conditioning regimen [3-6] or truly nonmyeloablative HCT (NMHCT) [7-10], in which the main mechanism of tumor eradication has been shifted from high-dose cytotoxic agents to the graft-vs-tumor effects [11]. Because of the mild conditioning regimen given and the use of peripheral blood as the source of hematopoietic stem cells (PBSC), posttransplant myelosuppression has remained modest and transient after NMHCT $[7,12,13]$. 
Erythropoietin (EPO) is the critical regulatory factor of erythropoiesis. In patients with normal kidney function, serum EPO levels increase exponentially when an anemia develops [14]. The adequacy of EPO serum levels is best assessed by the observed/predicted $(\mathrm{O} / \mathrm{P})$ ratio, a value below 1 indicating that EPO production is lower than expected for the degree of anemia [15]. After high-dose chemotherapy, serum EPO levels first rapidly increase to disproportionately high levels for 1 to 3 weeks, with peak values usually observed in the first week after the conditioning regimen [16-18]. However, after classical allogeneic HCT, the EPO response to anemia then generally becomes impaired, resulting in inappropriately low EPO levels and prolonged anemia [16-20]. Numerous trials have shown that there is a major need for efficient erythropoiesis enhancement to alleviate chronic anemia and reduce the high transfusion requirements after HCT. However, recombinant human erythropoietin (rHuEPO) therapy offers minimal (in case of allogeneic HCT) or no (in case of autologous HCT) benefit when rHuEPO is started immediately after the transplant [21-32]. On the other hand, we have shown that rHuEPO was remarkably efficient when started around day 30 after transplantation with a myeloablative conditioning regimen, i.e., when endogenous EPO production becomes impaired, and this was true for both allogeneic [32] and autologous [20] HCT.

Contrary to conventional allogeneic HCT, NMHCT is not associated with endogenous EPO deficiency [33]. Rather, EPO O/P ratios remain well within the normal range over the whole posttransplant follow-up [33]. However, although both red blood cell (RBC) and platelet transfusion requirements are reduced in NMHCT compared to conventional PBSCT [12,34-36], many NMHCT recipients experience prolonged anemia and many of them still require RBC transfusions [12,34,36]. A pilot study has shown that early rHuEPO therapy could be effective in this setting [37].

We report here on 60 consecutive patients undergoing NMHCT. The first 14 patients did not receive rHuEPO (control group). We then carried out a prospective trial of rHuEPO therapy, starting on day 0 in a group of 19 patients and on day 30 posttransplant in another group of 27 patients. The aim of this phase II trial was to examine the potential of two schedules of rHuEPO therapy to correct anemia and reduce $\mathrm{RBC}$ transfusions in recipients of a NMHCT.

\section{Patients and methods}

\section{Patients}

We studied 60 patients receiving a PBSC $(n=59)$ or marrow $(n=$ 1) transplant after a nonmyeloablative conditioning regimen in 2002-2004 [12]. The minimal follow-up is 100 days. Patients' characteristics are detailed in Table 1. Conditioning consisted of 2 Gy total-body irradiation (TBI) alone $(n=24)$ or combined
Table 1. Patients' characteristics

\begin{tabular}{|c|c|c|c|c|}
\hline & $\begin{array}{l}\text { Control } \\
\text { group }\end{array}$ & $\begin{array}{l}\text { EPO } \\
\text { group } 1\end{array}$ & $\begin{array}{l}\text { EPO } \\
\text { group } 2\end{array}$ & $\begin{array}{c}p \\
\text { value }\end{array}$ \\
\hline Number & 14 & 27 & 19 & \\
\hline Age $(M \pm S D)$ & $56 \pm 13$ & $55 \pm 11$ & $55 \pm 7$ & NS \\
\hline Sex & & & & NS \\
\hline Males & 10 & 18 & 15 & \\
\hline Females & 4 & 9 & 4 & \\
\hline Disease & & & & NS* \\
\hline AML & 1 & 1 & 3 & \\
\hline CML & 2 & 2 & 1 & \\
\hline MDS & 1 & 7 & 2 & \\
\hline Myelofibrosis & 0 & 1 & 0 & \\
\hline NHL & 5 & 9 & 6 & \\
\hline $\mathrm{HD}$ & 1 & 0 & 1 & \\
\hline CLL & 1 & 1 & 0 & \\
\hline MM & 1 & 5 & 3 & \\
\hline $\mathrm{RCC}$ & 2 & 1 & 3 & \\
\hline Disease status & & & & NS \\
\hline $\mathrm{CR}$ & 5 & 3 & 4 & \\
\hline No CR & 9 & 24 & 15 & \\
\hline Prior autologous HCT & & & & NS \\
\hline Yes & 6 & 13 & 10 & \\
\hline No & 8 & 14 & 9 & \\
\hline Donor type & & & & NS** \\
\hline HLA-identical sibling & 10 & 13 & 6 & \\
\hline Other related & 1 & 1 & 1 & \\
\hline HLA-identical unrelated & 3 & 13 & 12 & \\
\hline ABO compatibility & & & & NS \\
\hline Identical & 9 & 14 & 11 & \\
\hline Major mismatch & 4 & 7 & 2 & \\
\hline Minor mismatch & 1 & 6 & 6 & \\
\hline Conditioning regimen & & & & NS \\
\hline 2 Gy TBI & 6 & 11 & 7 & \\
\hline 2 Gy TBI + fludarabine & 5 & 13 & 10 & \\
\hline $\begin{array}{l}\text { Fludarabine }+ \\
\quad \text { cyclophosphamide }\end{array}$ & 3 & 3 & 2 & \\
\hline Graft manipulation & & & & NS \\
\hline None & 5 & 13 & 11 & \\
\hline CD8 depletion & 6 & 12 & 6 & \\
\hline CD34 selection & 3 & 2 & 2 & \\
\hline Baseline hemoglobin (g/dL) & $11.2 \pm 1.4$ & $10.5 \pm 2.3$ & $10.2 \pm 1.4$ & 0.3079 \\
\hline \multicolumn{5}{|l|}{$\begin{array}{l}\text { Baseline serum } \\
\text { creatinine }(\mathrm{mg} / \mathrm{L})\end{array}$} \\
\hline Day $0(\mathrm{M} \pm \mathrm{SD})$ & $9.5 \pm 4.1$ & $9.6 \pm 3.9$ & $11.5 \pm 4.7$ & NS \\
\hline Day $28(\mathrm{M} \pm \mathrm{SD})$ & $11.5 \pm 2.9$ & $12.4 \pm 3.7$ & $14.6 \pm 5.9$ & NS \\
\hline
\end{tabular}

AML, acute myeloid leukemia; CML, chronic myeloid leukemia; MDS, myelodysplastic syndrome; NHL, non-Hodgkin's lymphoma; HD, Hodgkin's disease; CLL, chronic lymphocytic leukemia; MM, multiple myeloma; $\mathrm{RCC}$, renal cell carcinoma; $\mathrm{CR}$, complete remission; TBI, total-body irradiation; M, mean; NS, not significant.

*Comparison between myeloid malignancies, lymphoid malignancies, and solid tumors.

$* * p=0.077$.

with $90 \mathrm{mg} / \mathrm{m}^{2}$ fludarabine for patients not heavily pretreated or unrelated transplants $(\mathrm{n}=28)$ or fludarabine and $3 \mathrm{~g} / \mathrm{m}^{2}$ cyclophosphamide (Flu-Cy) when previous irradiation precluded the use of TBI $(n=8)$ (Table 1). Posttransplant immunosuppression was carried out with cyclosporine (CsA) and mycophenolate mofetil (MMF) as previously reported [12,38]. Transplants were unmanipulated $(n=29)$ or CD8-depleted $(n=24)$ or CD34-selected 
PBSC $(n=7)$ as part of two consecutive NMHCT protocols. The trigger values for $\mathrm{RBC}$ and platelet transfusion were $8.0 \mathrm{~g} / \mathrm{dL}$ and $15 \times 10^{9} / \mathrm{L}$, respectively. Granulocyte colony-stimulating factor (G-CSF) $(5 \mu \mathrm{g} / \mathrm{kg} / \mathrm{d})$ was administered when the granulocyte count was below $1.0 \times 10^{9} / \mathrm{L}$. The Ethics Committee of the University of Liege approved the study protocols for NMHCT and rHuEPO therapy. Written informed consent was obtained from all patients.

\section{RHuEPO therapy}

The first 14 NMHCT recipients did not receive $\mathrm{rHuEPO}$ (control group) and were previously reported [33]. For the prospective phase II trial, we decided to start rHuEPO on day 30 (EPO group $1, \mathrm{n}=27$ ), because we had previously shown that this approach was very effective after myeloablative conditioning and transplantation of autologous [20,39] or allogeneic [18] HCT. If there was an active complication (infection, GVHD, etc.) on day 30 , the introduction of rHuEPO was delayed until it resolved. Hence the median day for onset of rHuEPO therapy was day 32 in this group. After observing that the nonmyeloablative conditioning regimen caused only mild myelosuppression that would probably not hamper the efficacy of rHuEPO, the protocol was amended so that rHuEPO was then scheduled to start on day 0 in a third cohort of 19 patients (EPO group 2). rHuEPO (Neorecormon, Roche, Basel, Switzerland) was administered subcutaneously once weekly at a dose of $500 \mathrm{U} / \mathrm{kg} / \mathrm{wk}$ with the aim of achieving hemoglobin $(\mathrm{Hb})$ levels of $13 \mathrm{~g} / \mathrm{dL}$. A major response (responder) was defined by an $\mathrm{Hb}$ increment greater than $2 \mathrm{~g} / \mathrm{dL}$ without transfusion needs [14]. The response was considered as complete (corrector) when the $\mathrm{Hb}$ reached the target value of $13 \mathrm{~g} / \mathrm{dL}$. Once the target $\mathrm{Hb}(13 \mathrm{~g} / \mathrm{dL})$ was achieved, the dose of rHuEPO was reduced so as to use the lowest dose capable of maintaining the $\mathrm{Hb}$ between 12 and $14 \mathrm{~g} / \mathrm{dL}$. If no major response was achieved after a total of 80 days of treatment, rHuEPO was discontinued. Patients received intravenous iron (Venofer, [Vifor, St. Gallin, Switzerland] $600 \mathrm{mg}$ in 3 divided weekly doses) if transferrin saturation fell below $20 \%$, unless the target $\mathrm{Hb}$ was already achieved. Control patients never received intravenous iron.

\section{Laboratory analyses}

Laboratory data were monitored weekly. Complete blood counts were determined in an Advia cell counter (Bayer, Tarrytown, NJ, USA). Serum erythropoietin (EPO) levels were measured just before treatment by a commercially available radioimmunoassay (Incstar Corp., Stillwater, MN, USA). Based on regression equations obtained in appropriate reference subjects between Hct on the one hand and log (EPO) on the other, predicted log (EPO) values were derived for each Hct and O/P ratios of observed/predicted EPO values were calculated [17]. The mean $( \pm$ $\mathrm{SD}) \mathrm{EPO} \mathrm{O} / \mathrm{P}$ ratio in a cohort of 31 normal donors was $1.03 \pm$ 0.08 . Serum soluble transferrin receptor (sTfR), a quantitative measure of total erythropoietic activity, was measured by a commercially available ELISA (R\&D, Minneapolis, MN, USA). Normal values range from 3000 to $7000 \mu \mathrm{g} / \mathrm{L}$. Serum iron, transferrin saturation, and ferritin were measured by routine methods. The degree of donor chimerism was assessed on days 28 and 42 posttransplant in myeloid cells and $\mathrm{T}$ cells using fluorescence in situ hybridization (FISH) with X- and Y- specific probes in case of sex mismatch or PCR-based analysis of polymorphic microsatellite regions in case of sex match.

\section{Statistical analysis}

To ensure better homogeneity of the results, Hb, sTfR, and reticulocytes were normalized relative to their value on the day of transplantation. Unpaired and paired Student's $t$-tests as well as two-way ANOVA (using EPO group and time as variables) were used to compare parameters in the 3 groups. Welsh's correction was used in case of unequal variance. In the first month posttransplant, patients in EPO group 1 received no rHuEPO and were thus considered as controls. To increase the statistical power of the study, the protocol scheduled for a comparison of patients receiving rHuEPO from day 1 posttransplant (EPO group 2) with patients receiving no $\mathrm{rHuEPO}$ during this period (control group + EPO group 1). After the first month, comparisons were made between the control group and either patients in EPO group 1 or patients in EPO group 2. Number of transfusions in the same group over time or in different groups of patients was compared using Wilcoxon matched pair or Mann-Whitney $U$ tests, respectively. Times to response to rHuEPO therapy were studied by life-table analyses and Wilcoxon rank tests were used for comparisons between groups. For patients included in the control group, time to achieve $\mathrm{Hb}$ levels of 12 and $13 \mathrm{~g} / \mathrm{dL}$ as well as time to achieve a $2 \mathrm{~g} / \mathrm{dL} \mathrm{Hb}$ increment were calculated both from day 0 (for comparison with EPO group 2) and from day 30 (for comparison with EPO group 1) after HCT. Patients who experienced graft rejection $(n=2)$, severe hemolysis or hemorrhage $(n=8)$, and/or progression of their disease $(n=9)$ were censured at time of these events. In particular, all patients with graft failure or disease progression rapidly developed hematopoietic failure with neutropenia and renewed transfusion dependence. Clinical variables associated with response to $\mathrm{rHuEPO}$ were first analyzed by $\chi^{2}$ tests. Univariate as well as multivariate (incorporating variables identified as significant in univariate analysis) Cox regression models were then performed. Statistical analyses were carried out with Graphpad Prism (Graphpad Software, San Diego, CA, USA) and SAS (SAS Institute, Cary, NC, USA) software.

\section{Results}

\section{Erythropoiesis}

Graft composition and speed of engraftment were not significantly different among the 3 groups (Table 2). There was no significant difference in platelet or neutrophil counts throughout the posttransplant course between patients receiving rHuEPO or not. In the first 30 days posttransplant, $\operatorname{sTfR}(p=0.0034)$, reticulocytes $(p=0.0001)$, and $\mathrm{Hb}$ $(p<0.0001)$ values were significantly higher in EPO group 2 (rHuEPO from day 0) compared to untreated patients (control group and EPO group 1) (Fig. 1). Between day 30 and day 120, whereas erythropoiesis (as assessed by sTfR) remained stable in the control group, it expanded very rapidly above the upper normal limit for STfR in the 2 cohorts of patients receiving $\mathrm{rHuEPO}(p<0.0001)$ (Fig. 1). Reticulocytes similarly increased significantly compared to controls ( $p=0.0173$ ). This expansion of erythropoietic activity translated into significantly more favorable $\mathrm{Hb}$ values $(p<0.0001)$. Because it was measured 
Table 2. Graft composition and hematopoietic recovery

\begin{tabular}{|c|c|c|c|}
\hline & Control group & EPO group 1 & EPO group 2 \\
\hline \multicolumn{4}{|l|}{ Graft composition (mean $\pm \mathrm{SD}$ ) } \\
\hline $\mathrm{CD} 34^{+}$cells $\left(\times 10^{6} / \mathrm{kg}\right)$ & $5.66 \pm 2.75$ & $5.99 \pm 3.06$ & $5.39 \pm 2.65$ \\
\hline BFU-E $\left(\times 10^{4} / \mathrm{kg}\right)$ & $101.1 \pm 71.7$ & $131.3 \pm 80.3$ & $109.6 \pm 55.9$ \\
\hline Days to $1 \%$ reticulocytes (median [range]) & $16[1-38]$ & $15[1-42]$ & $11[1-38]$ \\
\hline Days to last RBC transfusion (median [range]) & $6[1-25]$ & 13 [1-53] & $11[1-62]$ \\
\hline Days to $20 \times 10^{9} / \mathrm{L}$ platelets (median [range]) & $4[1-19]$ & $6[1-31]$ & $6[1-31]$ \\
\hline Days to $100 \times 10^{9} / \mathrm{L}$ platelets (median [range]) & $12[1-43]$ & $16[1-62]$ & $14[1-62]$ \\
\hline Days to last platelet transfusion (median [range]) & $5[1-30]$ & $5[1-25]$ & $5[1-25]$ \\
\hline Number of days of G-CSF (median [range]) & $3[0-10]$ & $6[0-17]$ & $5[0-17]$ \\
\hline Days to $0.5 \times 10^{9} / \mathrm{L}$ neutrophils (median [range]) & $7[1-24]$ & $5[1-14]$ & $4[1-13]$ \\
\hline Days to $1.0 \times 10^{9} / \mathrm{L}$ neutrophils (median [range]) & $11[1-38]$ & $8[1-22]$ & $8[1-22]$ \\
\hline
\end{tabular}

"Days to" means days from transplant to the event. Day 1 means that either counts never decreased below stated level or transfusions were never administered. All differences are nonsignificant.

immediately after the conditioning regimen in EPO group 2 whereas it was measured 4 weeks later in EPO group 1, the pretreatment $\mathrm{O} / \mathrm{P}$ ratio was higher in EPO group $2(1.11 \pm$ 0.22 vs $0.91 \pm 0.25, p=0.0302$ ).

\section{Clinical response}

In the first month after transplantation, mean \pm SD number of RBC transfusions was $1.7 \pm 0.4$ in patients who did not receive rHuEPO (control group + EPO group 1, very similar in the 2 groups) and $0.5 \pm 0.3$ in patients who received it starting on day 0 (EPO group 2) ( $p=0.0169)$. Between days 30 and 100, there were $1.6 \pm 0.7 \mathrm{RBC}$ transfusions in controls vs $1.2 \pm 0.4$ in patients receiving $\mathrm{rHuEPO}(p=$ $0.5919)$. Between days 100 and 180, the figures were 0.7 \pm 0.5 in controls vs $0.5 \pm 0.3$ in patients receiving $\mathrm{rHuEPO}$ $(p=0.8186)$. Clinical response with reduction in transfusion needs was thus observed only in the group of patients receiving $\mathrm{rHuEPO}$ starting on the day of transplantation. During the first month posttransplant, the mean transfusion cost decreased from $302 \pm 422$ EUR in patients receiving no $\mathrm{rHuEPO}$ to $89 \pm 207 \mathrm{EUR}$ in patients receiving $\mathrm{rHuEPO}$ $(p=0.022)$. However, because of the monthly cost of treatment at full dose (1276 EUR/patient), rHuEPO remains much more expensive than iterative transfusion.

The K-M probability of achieving a $\mathrm{Hb}$ increment of at least $2 \mathrm{~g} / \mathrm{dL}$ at 8,12 , or 16 weeks was $14 \%, 14 \%$, and $14 \%$ in controls, vs $28 \%, 64 \%$, and $64 \%$ respectively in EPO group $2(p=0.0082)$ and $19 \%, 19 \%$, and $69 \%$ respectively in EPO group 1 ( $p=0.0125$ ) (Fig. 2). The probability of achieving a $\mathrm{Hb}$ value of $13 \mathrm{~g} / \mathrm{dL}$ at 8,12 , and 16 weeks was $0 \%, 0 \%$, and $0 \%$ in controls, vs $17 \%, 34 \%$, and $45 \%$ in EPO group $2(p=0.0103)$ and $8 \%, 26 \%$, and $49 \%$ in EPO group 1 ( $p=0.0031$ ) (Fig. 2). Eventually, 17\% of the patients in the control group vs $56 \%$ in EPO group 2 $(p=0.0145)$ and $64 \%$ in EPO group $1(p=0.0031)$ achieved an $\mathrm{Hb}$ value of $13 \mathrm{~g} / \mathrm{dL}$ (Fig. 2). This was obtained after a median of 21 weeks in both EPO groups. These comparable responses among the 2 groups were achieved despite a slight difference between pretreatment $\mathrm{Hb}$ values
$(9.3 \pm 1.3$ in group 1 (day 28 posttransplant) vs $10.2 \pm 1.4$ in group 2 (day 0 of transplantation), $p=0.0359$ ).

Similar proportions of patients needed intravenous iron supplementation in EPO group $1(51 \%)$ and in EPO group $2(42 \%)$. All patients in all the 3 groups were alive at day 120 posttransplant.

\section{Variables associated with response to $\mathrm{rH} E \mathrm{EPO}$}

Because the response rate observed after NMSCT was significantly lower than the one obtained after HCT with a myeloablative conditioning regimen, we attempted at identifying factors that could be associated with response to rHuEPO therapy. We considered all patients receiving rHuEPO and classified them in 2 groups according to whether they achieved a major ( $\geq 2 \mathrm{~g} / \mathrm{dL}$ Hb increment) or a complete $(\mathrm{Hb} \geq 13 \mathrm{~g} / \mathrm{dL})$ response or not. Variables analyzed were baseline clinical characteristics (age, sex, prior autologous HCT, disease and disease status, conditioning regimen, graft manipulation, donor type, ABO compatibility, HLA matching) and biological parameters (EPO $\mathrm{O} / \mathrm{P}$ ratio, $\mathrm{Hb}$, sTfR, retics, creatinine, serum iron, transferrin saturation, ferritin, platelets, neutrophils), events occurring on rHuEPO therapy (aGVHD, CMV and other infections, intravenous iron administration), and posttransplant myeloid and T-cell chimerism (Table 3). The median T-cell chimerism was $75 \%$ on day 28 and $75 \%$ on day 42 . To obtain the optimal cutoff for T-cell and myeloid chimerism values, we first examined several cutoffs $(50 \%, 60 \%$, $70 \%, 80 \%, 90 \%$, and $95 \%$ ) on days 28 and 42 in univariate analysis. The optimal cutoff was then selected for use in multivariate analysis.

Clinically relevant prognostic factors were first tested by Student's $t$-tests. Age, sex, previous autologous transplant, disease, disease status, conditioning regimen, and renal function did not impact on response (data not shown, all $p$ values $>0.10)$. A conditioning regimen including TBI or CD8 depletion of the graft generated lower probabilities of major or complete response to rHuEPO therapy (Table 3). The degrees of myeloid or lymphoid chimerism on days 28 

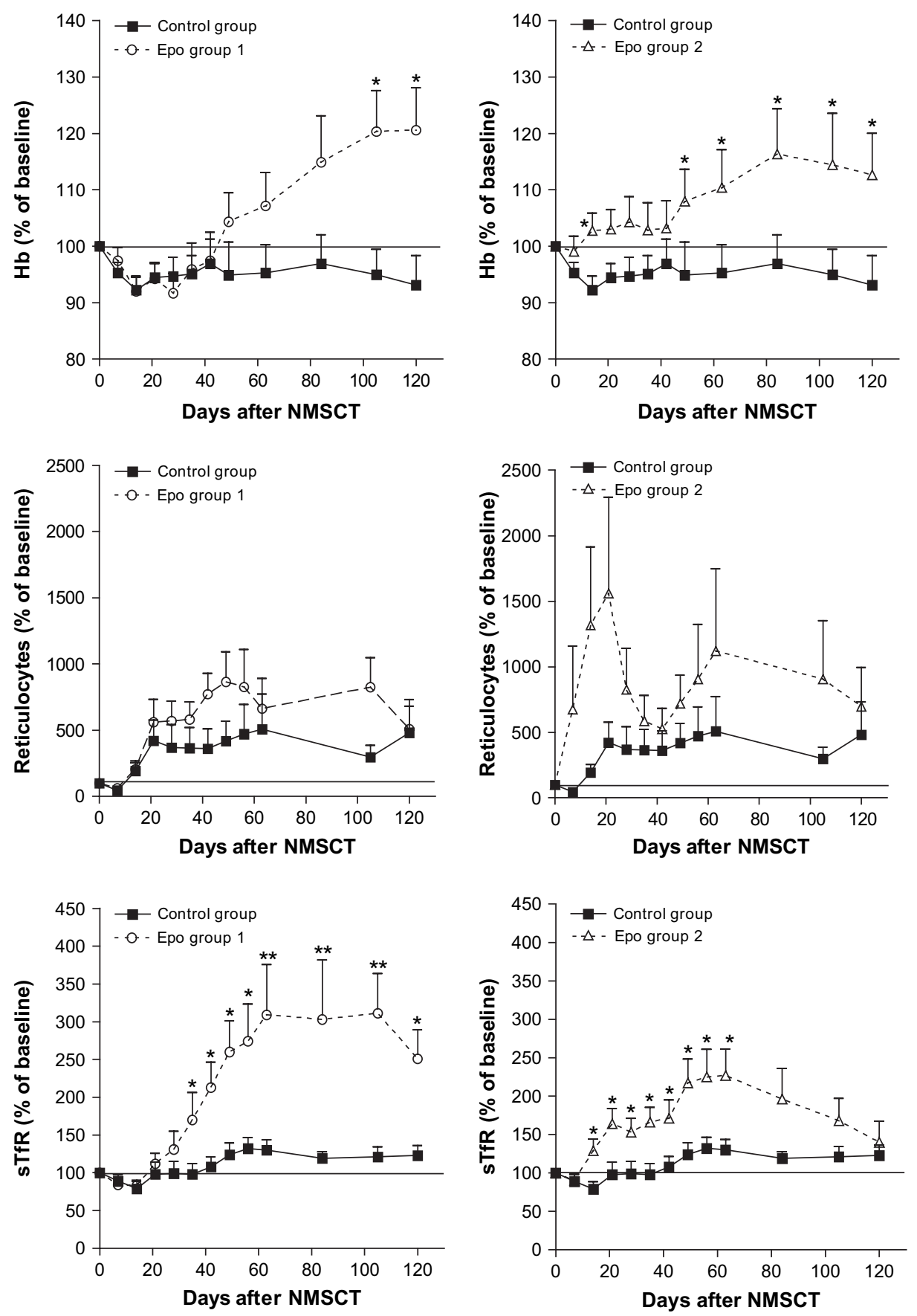

Figure 1. Hb levels, reticulocyte counts, and sTfR levels after transplantation. Values are normalized relative to their value on the day of transplantation. The left panels provide the evolution in EPO group 1 (rHuEPO started on day 30) and right panels the evolution in EPO group 2 (rHuEPO started on day 0). $p$ values are given for comparisons with the control group at any particular time point by Student's $t$-tests $(*<0.05, * *<0.01, * * *<0.001)$.

and 42 were also important determinants of response to rHuEPO. Patients with a myeloid chimerism above $90 \%$ and even more so T-cell chimerism above $60 \%$ had a significantly higher probability of achieving a major or complete response (Table 3). No other factor, and in particular not baseline EPO, was associated with response (Table 3).

Univariate Cox regression models were then performed with all variables listed above, including all biological pa- rameters as measured on days 0 and 28 of rHuEPO treatment. Factors selected based on these univariate analysis (TBI, CD8 depletion, day-42 T-cell chimerism, day-42 myeloid chimerism, $\mathrm{Hb}$ and platelets on day 0 of rHuEPO therapy, reticulocytes on day 28 of rHuEPO therapy for major response; and TBI, CD8 depletion, day-42 T-cell chimerism for complete response) were then tested in multivariate Cox models (Table 4). T-cell chimerism above $60 \%$ on day 42 

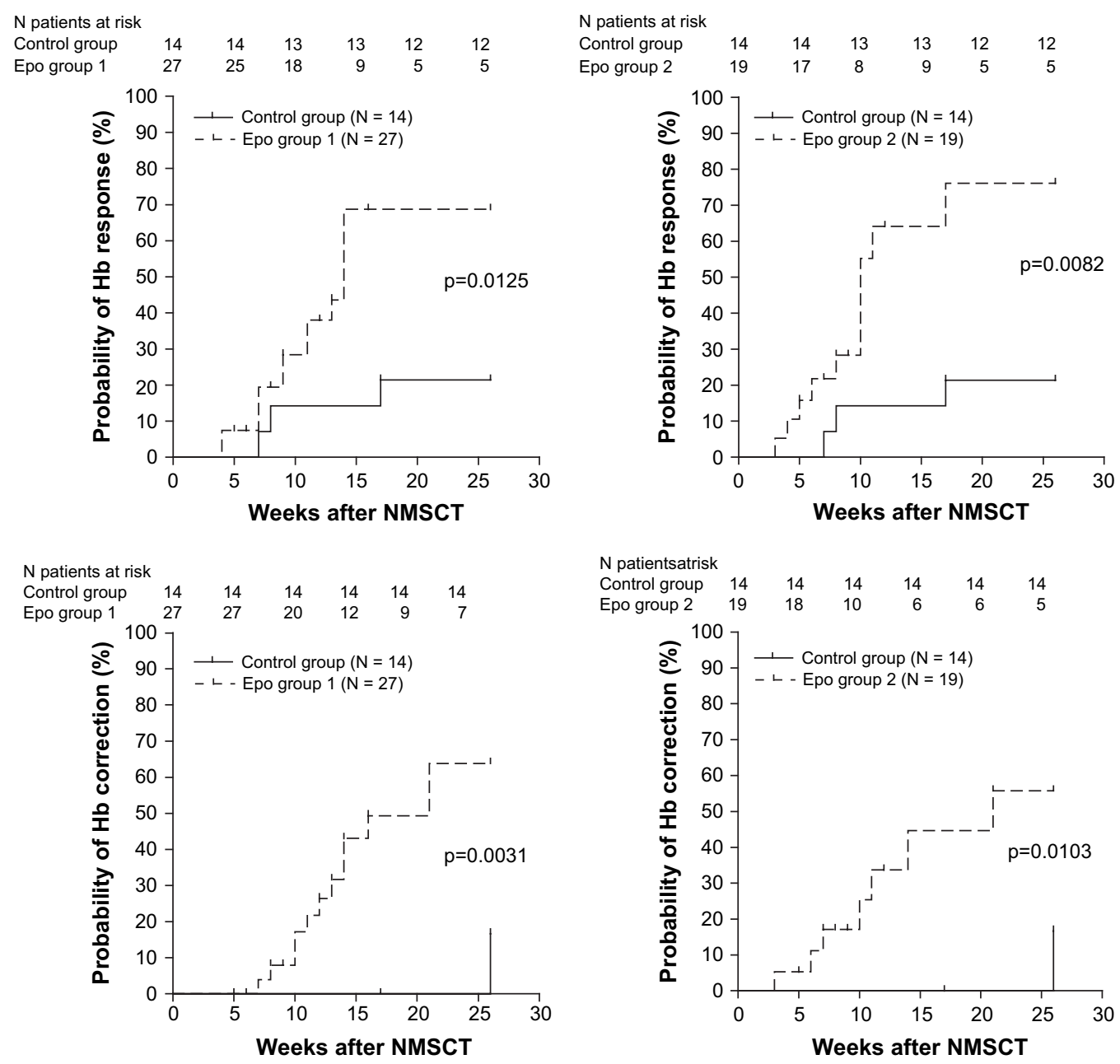

Figure 2. Kaplan-Meier plots of time to major response ( $\mathrm{Hb}$ increasing by $2 \mathrm{~g} / \mathrm{dL}=\mathrm{Hb}$ response) and time to complete response $(\mathrm{Hb} \geq 13 \mathrm{~g} / \mathrm{dL}=\mathrm{Hb}$ correction) from day of transplantation. The left panels provide the evolution in EPO group 1 (rHuEPO started on day 30) and right panels the evolution in EPO group 2 (rHuEPO started on day 0 ), compared to the control group.

was the variable most associated with $\mathrm{Hb}$ response $(p=$ $0.0034)$ or $\mathrm{Hb}$ correction $(p=0.0217)$. Only lower baseline $\mathrm{Hb}$ levels were also associated with $\mathrm{Hb}$ response $(p=$ 0.011) but not with $\mathrm{Hb}$ correction.

\section{Discussion}

In this study, we examined the effect of rHuEPO therapy after allogeneic transplantation with a nonmyeloablative conditioning regimen. The majority of NMSCT patients responded to $\mathrm{rHuEPO}$ with $\mathrm{Hb}$ increments greater than 2 $\mathrm{g} / \mathrm{dL}$ and correction of anemia. This was clearly preceded by stimulation of erythropoietic activity as assessed by sTfR levels, whereas reticulocyte counts, as in other rHuEPO trials after HCT [20,32], were less reliably increased. Although we did not formally compare these results with response to rHuEPO after conventional transplantation [18,32], responses appeared slower and overall response rates lower in NMSCT recipients. Obviously, there are major differences, such as age, disease status, previous auto-HCT, and conditioning regimen, between NMSCT and conventional transplants that could limit the scope of comparisons. Nevertheless, as these variables were found to have no impact on response to rHuEPO in this as well as other studies, potential explanations can still be examined.

The reason for this discrepancy between NMSCT and conventional transplants could relate to differences in the pathophysiology of endogenous EPO production. Indeed, we have previously shown that, while endogenous EPO levels became rapidly inappropriately low for at least several months after conventional transplants [16-20], they remained adequate during the whole posttransplant course after NMSCT [33]. Therefore rHuEPO could be predicted to be less efficient after NMSCT. However, among NMSCT patients, lower endogenous EPO levels were not associated with better response to rHuEPO therapy. On the other hand, as previous studies had shown that after conventional 
Table 3. Clinical variables analyzed (see text) by $t$-tests for association with major $(\mathrm{Hb}+2 \mathrm{~g} / \mathrm{dL})$ and complete $(\mathrm{Hb} \geq 13 \mathrm{~g} / \mathrm{dL})$ response to $\mathrm{rHuEPO}$

\begin{tabular}{|c|c|c|c|c|}
\hline & \multicolumn{2}{|c|}{ Major response } & \multicolumn{2}{|c|}{ Complete response } \\
\hline & $\mathrm{n}(\%)$ & $p$ value & $\mathrm{n}(\%)$ & $p$ value \\
\hline \multicolumn{5}{|l|}{ TBI } \\
\hline Yes & $19(46 \%)$ & \multirow[t]{2}{*}{0.0233} & $14(34 \%)$ & \multirow[t]{2}{*}{0.0047} \\
\hline No & $5(100 \%)$ & & $5(100 \%)$ & \\
\hline \multicolumn{5}{|l|}{ Graft manipulation } \\
\hline No & $17(71 \%)$ & \multirow[t]{3}{*}{$0.0380 *$} & $13(54 \%)$ & \multirow[t]{3}{*}{$0.0926^{* *}$} \\
\hline CD8 depletion & $5(28 \%)$ & & $4(22 \%)$ & \\
\hline CD34 selection & $2(50 \%)$ & & $2(50 \%)$ & \\
\hline \multicolumn{5}{|l|}{ Donor type } \\
\hline Related & $10(45 \%)$ & \multirow[t]{2}{*}{0.3820} & $9(41 \%)$ & \multirow[t]{2}{*}{0.9580} \\
\hline Unrelated & $14(58 \%)$ & & $10(42 \%)$ & \\
\hline \multicolumn{5}{|l|}{ ABO compatibility } \\
\hline ABO identical & $14(56 \%)$ & \multirow[t]{2}{*}{0.5700} & $11(44 \%)$ & \multirow[t]{2}{*}{0.6850} \\
\hline Not ABO identical & $10(48 \%)$ & & $8(38 \%)$ & \\
\hline \multicolumn{5}{|l|}{ HLA } \\
\hline Matched & $21(51 \%)$ & \multirow[t]{2}{*}{0.7100} & $16(39 \%)$ & \multirow[t]{2}{*}{0.3680} \\
\hline Mismatched & $3(60 \%)$ & & $3(60 \%)$ & \\
\hline \multicolumn{5}{|l|}{ EPO O/P ratio } \\
\hline$<0.9$ & $9(52 \%)$ & \multirow[t]{2}{*}{0.9360} & $13(54 \%)$ & \multirow[t]{2}{*}{0.0642} \\
\hline$\geq 0.9$ & $15(52 \%)$ & & $6(27 \%)$ & \\
\hline \multicolumn{5}{|c|}{ Acute GVHD (grade II-IV) } \\
\hline Yes & $10(56 \%)$ & \multirow[t]{2}{*}{0.7120} & $7(39 \%)$ & \multirow[t]{2}{*}{0.7890} \\
\hline No & $14(50 \%)$ & & $12(43 \%)$ & \\
\hline \multicolumn{5}{|l|}{ CMV infection } \\
\hline Yes & $9(39 \%)$ & \multirow[t]{2}{*}{0.0765} & $9(41 \%)$ & \multirow[t]{2}{*}{0.9580} \\
\hline No & $15(65 \%)$ & & $10(42 \%)$ & \\
\hline Other infection & & & & \\
\hline Yes & $7(41 \%)$ & 0.2520 & $7(39 \%)$ & 0.7890 \\
\hline No & $17(59 \%)$ & & $12(43 \%)$ & \\
\hline T-cell chimerism (day & & & & \\
\hline$\geq 60 \%$ & $20(69 \%)$ & 0.0029 & $15(52 \%)$ & 0.0608 \\
\hline$<60 \%$ & $4(24 \%)$ & & $4(24 \%)$ & \\
\hline T-cell chimerism (day & & & & \\
\hline$\geq 60 \%$ & $20(71 \%)$ & 0.0018 & $16(57 \%)$ & 0.0093 \\
\hline$<60 \%$ & $4(23 \%)$ & & $3(18 \%)$ & \\
\hline Myeloid chimerism $(\mathrm{d}$ & & & & \\
\hline$\geq 90 \%$ & $21(63 \%)$ & 0.0131 & $16(48 \%)$ & 0.1150 \\
\hline$<90 \%$ & $3(23 \%)$ & & $3(23 \%)$ & \\
\hline Myeloid chimerism (c & & & & \\
\hline$\geq 90 \%$ & $21(61 \%)$ & 0.0046 & $16(47 \%)$ & 0.2480 \\
\hline$<90 \%$ & $3(27 \%)$ & & $3(27 \%)$ & \\
\hline
\end{tabular}

$* p=0.0081$ for no manipulation vs any manipulation, and $p=0.0079$ for CD8 depletion vs all others.

$*^{*} p=0.0640$ for no manipulation vs any manipulation, and $p=0.0350$ for CD8 depletion vs all others.

transplantation the benefit of rHuEPO therapy was minimal when it was given early posttransplant [21-32] but could be optimized when started after day 30 [32], we first administered rHuEPO starting on day 30 after the transplant. However, as the degree of myelosuppression after NMSCT was mild [13], we also started rHuEPO therapy on the day of transplantation in another group of patients, achieving complete $\mathrm{Hb}$ correction at similar speed and frequency. Further-
Table 4. Multivariate analysis of probability of response to rHuEPO

\begin{tabular}{lccc}
\hline & $\mathrm{RR}$ & $95 \% \mathrm{CI}$ & $p$ value \\
\hline $\begin{array}{l}\text { Major response }(\mathrm{Hb}+2 \mathrm{~g} / \mathrm{dL}) \\
\quad \begin{array}{l}\text { Day-42 T-cell chimerism } \\
(\geq 60 \% \text { vs }<60 \%)\end{array}\end{array}$ & 5.33 & $1.74-16.33$ & 0.0034 \\
$\quad \begin{array}{l}\text { Baseline Hb (continuous) } \\
\text { Complete response }(\mathrm{Hb} \geq 13 \mathrm{~g} / \mathrm{dL}) \\
\quad \begin{array}{l}\text { Day-42 T-cell chimerism } \\
(\geq 60 \% \text { vs }<60 \%)\end{array}\end{array}$ & 0.63 & $0.48-0.83$ & 0.0011 \\
\hline
\end{tabular}

more, transfusion requirements were decreased only in the first month posttransplant if rHuEPO was started on day 0 , a period when endogenous EPO levels are exaggerated for the degree of anemia. All these findings indicate that, after NMSCT, the pathophysiology of endogenous EPO production does not account for response to rHuEPO therapy.

There is only a single other study investigating the impact of rHuEPO therapy starting on day 1 after NMSCT in 20 patients [37]. All of them, vs only $63 \%$ of controls, achieved an $\mathrm{Hb}$ level greater than $11 \mathrm{~g} / \mathrm{dL}$ after a median of 30 days and $70 \%$ of them, vs only $19 \%$ of controls, maintained it in the second month. Comparison with our trial is difficult because they did not report on more standard response criteria (proportion of patients achieving $\mathrm{Hb}$ response or $\mathrm{Hb}$ correction), used a more intensive conditioning regimen, and provided systematic oral iron supplementation compared to more targeted intravenous iron supplementation in our trial. For patients receiving RBC transfusions, their use of rHuEPO was associated with a trend towards reduced requirements [37]. The same authors also previously showed that RBC transfusion needs after NMSCT correlated inversely with pretransplant $\mathrm{Hb}$ levels [36]. In our trial, we found that baseline $\mathrm{Hb}$ inversely correlated with response to rHuEPO therapy. However, the latter may be explained in part by methodological reasons, because more anemic patients had more opportunity to increase their $\mathrm{Hb}$ by at least $2 \mathrm{~g} / \mathrm{dL}$ before per-protocol rHuEPO dose reductions could take place.

We sought to identify patient and transplant characteristics associated with response. A major ABO mismatch between donor and recipient is classically associated with delayed recovery of erythropoietic activity because of direct inhibition of donor erythroid progenitors and precursors by residual recipient $\mathrm{ABO}$ antibodies [40], but this did not impair response to $\mathrm{rHuEPO}$. Previous reports have also indicated that a major ABO mismatch does not prevent appropriate response to $\mathrm{rHuEPO}$ [41]. Because of the major inflammatory response they elicit, infections often result in a delay or loss of response to rHuEPO therapy in other settings $[14,17,42]$, but not in our NMSCT patients. The use of an unrelated donor increases the risk of infection as well as of acute GVHD, a complication associated with further inhibition of endogenous EPO production [16,17,43] and a cytokine storm potentially inhibiting marrow 
erythropoiesis [44], but this did not prevent response to rHuEPO in our patients.

Most interestingly, the degree of donor chimerism was of utmost importance for response to rHuEPO. Although a high degree of myeloid donor chimerism $(>90 \%)$ was also associated with better response, a high proportion of lymphocytes of donor origin was the only variable associated both with $\mathrm{Hb}$ response and $\mathrm{Hb}$ correction in multivariate analysis. The optimal cutoff value and timing were found to be donor T-cell chimerism greater than $60 \%$ on day 42. Use of TBI in the conditioning regimen and CD8 depletion of the graft were associated with poorer response to rHuEPO in univariate but not multivariate analysis, most probably because their effects were mostly related to the lower chimerism levels they generated. One can only speculate on the potential explanations for this observation. One attractive hypothesis is that erythropoietic progenitors and precursors, which are largely of donor origin soon after NMSCT [45], could be inhibited by residual recipient lymphocytes. These lymphocytes could become activated against donor antigens, thereby also secreting excess amounts of inflammatory cytokines that could in turn inhibit marrow erythropoietic activity [44]. The higher the proportion of recipient lymphocytes (decreasing chimerism), the stronger this inhibitory effect could be. This hypothesis could be further supported by the fact that patients receiving CD8-depleted grafts responded less well to rHuEPO therapy. On the other hand, as T-cell chimerism is generally immediately fully of donor origin after allogeneic transplantation with a myeloablative conditioning regimen [46,47], the absence of such an inhibitory effect of residual recipient lymphocytes could also provide a reasonable explanation on why the response rate to rHuEPO therapy is much higher after conventional transplantation. An alternative explanation could be that recently irradiated marrow may be less responsive to cytokine stimulation and that lower-level chimeras could require proportionally more recovery from irradiated marrow compared with high-level chimeras. However, this would apply to myeloid rather than lymphoid chimerism.

Our phase II trial has provided proof of principle and preliminary efficacy data for a rational use of rHuEPO after NMHCT by showing $\mathrm{Hb}$ responses as well as a reduction in transfusion needs in the first 30 days posttransplant. One could argue that our patient population was quite heterogeneous for diagnosis, disease stage, conditioning regimen, donor type, and graft manipulation. This is true but we clearly showed that none of these factors significantly influenced response to rHuEPO. In addition, all previous studies of rHuEPO after HCT have included such heterogeneous groups of patients on the basis of the lack of any evidence that these pretransplant characteristics significantly affected posttransplant erythropoietic activity. This is even more evident in all major studies of rHuEPO given for the treatment of cancer- or chemotherapy-associated anemia. On the other hand, one could argue that an average transfusion rate of $4 \mathrm{U}$ over 6 months as observed in our untreated NMSCT recipients is quite moderate and that the clinical utility of rHuEPO would be limited. However, there is a need for effective prevention and the benefits of rHuEPO therapy are not limited to transfusion avoidance. To avoid the potential difficulties in interpreting the impact of rHuEPO therapy after transplantation, it is thus now justified to develop prospective, randomized trials that should investigate clinical endpoints previously shown to be improved by rHuEPO therapy in other settings, such as transfusion requirements and quality of life. In order to demonstrate a real impact on transfusions, our recommendation for such trials would be to start rHuEPO therapy on day 0 of the transplant at the standard dose of $500 \mathrm{U} /$ $\mathrm{kg} / \mathrm{wk}$, while adopting a strategy aiming at optimizing Tcell chimerism early on.

\section{Acknowledgment}

Frédéric Baron is Research Associate and Yves Beguin Research Director of the National Fund for Scientific Research (FNRS, Belgium). This work was supported in part by grants from the FNRS.

\section{References}

1. Baron F, Storb R. Allogeneic hematopoietic cell transplantation as treatment for hematological malignancies: a review. Springer Semin Immunopathol. 2004;26:71-94.

2. Kolb HJ, Schmidt C, Barrett AJ, Schendel DJ. Graft-versus-leukemia reactions in allogeneic chimeras. Blood. 2004;103:767-776.

3. Slavin S, Nagler A, Naparstek E, et al. Nonmyeloablative stem cell transplantation and cell therapy as an alternative to conventional bone marrow transplantation with lethal cytoreduction for the treatment of malignant and nonmalignant hematologic diseases. Blood. 1998;91:756-763.

4. Wong R, Giralt SA, Martin T, et al. Reduced intensity conditioning for unrelated donor hematopoietic stem cell transplantation as treatment of myeloid malignancies in patients older than 55 years of age. Blood. 2003;102:3052-3059.

5. Dreger P, Brand R, Hansz J, et al. Treatment-related mortality and graft-versus-leukemia activity after allogeneic stem cell transplantation for chronic lymphocytic leukemia using intensity-reduced conditioning. Leukemia. 2003;17:841-848.

6. Baron F, Beguin Y. Nonmyeloablative allogeneic hematopoietic stem cell transplantation. J Hematother Stem Cell Res. 2002;11:243-263.

7. McSweeney PA, Niederwieser D, Shizuru J, et al. Hematopoietic cell transplantation in older patients with hematologic malignancies: replacing high-dose cytotoxic therapy with graft-versus-tumor effects. Blood. 2001;97:3390-3400.

8. Niederwieser D, Maris M, Shizuru JA, et al. Low-dose total body irradiation (TBI) and fludarabine followed by hematopoietic cell transplantation (HCT) from HLA-matched or mismatched unrelated donors and postgrafting immunosuppression with cyclosporine and mycophenolate mofetil (MMF) can induce durable complete chimerism and sustained remissions in patients with hematological diseases. Blood. 2003;101:1620-1629.

9. Childs R, Clave E, Contentin N, et al. Engraftment kinetics after nonmyeloablative allogeneic peripheral blood stem cell transplantation: full donor T-cell chimerism precedes alloimmune response. Blood. 1999;94:3234-3241. 
10. Maris MB, Niederwieser D, Sandmaier BM, et al. HLA-matched unrelated donor hematopoietic cell transplantation after nonmyeloablative conditioning for patients with hematologic malignancies. Blood. 2003;102:2021-2030.

11. Baron F, Maris MB, Sandmaier BM, et al. Graft-versus-tumor effects after allogeneic hematopoietic cell transplantation with nonmyeloablative conditioning. J Clin Oncol. 2005;23:1993-2003.

12. Baron F, Baudoux E, Frere P, et al. Nonmyeloablative stem cell transplantation with CD8-depleted or CD34-selected peripheral blood stem cells. J Hematother Stem Cell Res. 2002;11:301-314.

13. Baron F, Baker JE, Storb R, et al. Kinetics of engraftment in patients with hematologic malignancies given allogeneic hematopoietic cell transplantation after nonmyeloablative conditioning. Blood. 2004; 104:2254-2262.

14. Beguin Y. Prediction of response and other improvements on the limitations of recombinant human erythropoietin therapy in anemic cancer patients. Haematologica. 2002;87:1209-1221.

15. Beguin Y, Clemons GK, Pootrakul P, Fillet G. Quantitative assessment of erythropoiesis and functional classification of anemia based on measurements of serum transferrin receptor and erythropoietin. Blood. 1993;81:1067-1076.

16. Beguin Y, Clemons GK, Oris R, Fillet G. Circulating erythropoietin levels after bone marrow transplantation: inappropriate response to anemia in allogeneic transplants. Blood. 1991;77:868-873.

17. Beguin Y, Oris R, Fillet G. Dynamics of erythropoietic recovery following bone marrow transplantation: role of marrow proliferative capacity and erythropoietin production in autologous versus allogeneic transplants. Bone Marrow Transplant. 1993;11:285-292.

18. Baron F, Frere P, Beguin Y. Once weekly recombinant human erythropoietin therapy is very efficient after allogeneic peripheral blood stem cell transplantation when started soon after engraftment. Haematologica. 2003;88:718-720.

19. Beguin Y, Baron F, Fillet G. Influence of marrow activity on serum erythropoietin levels after autologous hematopoietic stem cell transplantation. Haematologica. 1998;83:1076-1081.

20. Baron F, Frere P, Fillet G, Beguin Y. Recombinant human erythropoietin therapy is very effective after an autologous peripheral blood stem cell transplant when started soon after engraftment. Clin Cancer Res. 2003;9:5566-5572.

21. Steegmann JL, Lopez J, Otero MJ, et al. Erythropoietin treatment in allogeneic BMT accelerates erythroid reconstitution: results of a prospective controlled randomized trial. Bone Marrow Transplant. 1992; 10:541-546

22. Klaesson S, Ringden O, Ljungman P, Lonnqvist B, Wennberg L. Treatment with erythropoietin after allogeneic bone marrow transplantation: a randomized, double-blind study. Transplant Proc. 1994;26: 1827-1828.

23. Vannucchi AM, Bosi A, Grossi A, et al. Stimulation of erythroid engraftment by recombinant human erythropoietin in ABO-compatible, HLA-identical, allogeneic bone marrow transplant patients. Leukemia. 1992;6:215-219.

24. Vannucchi AM, Bosi A, Ieri A, et al. Combination therapy with GCSF and erythropoietin after autologous bone marrow transplantation for lymphoid malignancies: a randomized trial. Bone Marrow Transplant. 1996;17:527-531.

25. Locatelli F, Pedrazzoli P, Barosi G, et al. Recombinant human erythropoietin is effective in correcting erythropoietin-deficient anaemia after allogeneic bone marrow transplantation. Br J Haematol. 1992;80: 545-549.

26. Locatelli F, Zecca M, Ponchio L, et al. Pilot trial of combined administration of erythropoietin and granulocyte colony-stimulating factor to children undergoing allogeneic bone marrow transplantation. Bone Marrow Transplant. 1994;14:929-935.

27. Locatelli F, Zecca M, Pedrazzoli P, et al. Use of recombinant human erythropoietin after bone marrow transplantation in pediatric patients with acute leukemia: effect on erythroid repopulation in autologous versus allogeneic transplants. Bone Marrow Transplant. 1994;13:403-410.

28. Link H, Boogaerts MA, Fauser AA, et al. A controlled trial of recombinant human erythropoietin after bone marrow transplantation. Blood. 1994;84:3327-3335.

29. Biggs JC, Atkinson KA, Booker V, et al. Prospective randomised double-blind trial of the in vivo use of recombinant human erythropoietin in bone marrow transplantation from HLA-identical sibling donors. The Australian Bone Marrow Transplant Study Group. Bone Marrow Transplant. 1995;15:129-134.

30. Chao NJ, Schriber JR, Long GD, et al. A randomized study of erythropoietin and granulocyte colony-stimulating factor (G-CSF) versus placebo and G-CSF for patients with Hodgkin's and non-Hodgkin's lymphoma undergoing autologous bone marrow transplantation. Blood. 1994;83:2823-2828.

31. Sautois B, Baudoux E, Salmon JP, et al. Administration of erythopoietin and granulocyte colony-stimulating factor in donor/recipient pairs to collect peripheral blood progenitor cells (PBPC) and red blood cell units for use in the recipient after allogeneic PBPC transplantation. Haematologica. 2001;86:1209-1218.

32. Baron F, Sautois B, Baudoux E, Matus G, Fillet G, Beguin Y. Optimization of recombinant human erythropoietin therapy after allogeneic hematopoietic stem cell transplantation. Exp Hematol. 2002;30:546-554.

33. Baron F, Fillet G, Beguin Y. Erythropoiesis after nonmyeloablative stem-cell transplantation is not impaired by inadequate erythropoietin production as observed after conventional allogeneic transplantation. Transplantation. 2002;74:1692-1696.

34. Weissinger F, Sandmaier BM, Maloney DG, Bensinger WI, Gooley T, Storb R. Decreased transfusion requirements for patients receiving nonmyeloablative compared with conventional peripheral blood stem cell transplants from HLA-identical siblings. Blood. 2001;98:3584-3588.

35. Sorror ML, Maris MB, Storer B, et al. Comparing morbidity and mortality of HLA-matched unrelated donor hematopoietic cell transplantation after nonmyeloablative and myeloablative conditioning: influence of pretransplant comorbidities. Blood. 2004;104:961968.

36. Ivanov V, Faucher C, Mohty M, et al. Decreased RBCTs after reduced intensity conditioning allogeneic stem cell transplantation: predictive value of prior Hb level. Transfusion. 2004;44:501-508.

37. Ivanov V, Faucher C, Mohty M, et al. Early administration of recombinant erythropoietin improves hemoglobin recovery after reduced intensity conditioned allogeneic stem cell transplantation. Bone Marrow Transplant. 2005;36:901-906.

38. Baron F, Schaaf-Lafontaine N, Humblet-Baron S, et al. T-cell reconstitution after unmanipulated, CD8-depleted or CD34-selected nonmyeloablative peripheral blood stem-cell transplantation. Transplantation. 2003;76:1705-1713.

39. Baron F, Frere P, Fillet G, Beguin Y. Tandem high-dose therapy (HDT) for multiple myeloma: recombinant human erythropoietin therapy given between first and second HDT allows second peripheral blood stem cell transplantation without red blood cell transfusion. $\mathrm{Br} \mathrm{J}$ Haematol. 2003;123:103-105.

40. Rowley SD. Hematopoietic stem cell transplantation between red cell incompatible donor-recipient pairs. Bone Marrow Transplant. 2001; 28:315-321.

41. Santamaria A, Sureda A, Martino R, Domingo-Albos A, Muniz-Diaz E, Brunet S. Successful treatment of pure red cell aplasia after major ABO-incompatible T cell-depleted bone marrow transplantation with erythropoietin. Bone Marrow Transplant. 1997;20:1105-1107.

42. Danielson B. R-HuEPO hyporesponsiveness - who and why? Nephrol Dial Transplant. 1995;10(suppl 2):69-73.

43. Beguin Y, Loo M, R'Zik S, et al. Early prediction of response to recombinant human erythropoietin in patients with the anemia of renal failure by serum transferrin receptor and fibrinogen. Blood. 1993;82: 2010-2016. 
44. Means RT Jr. The anaemia of infection. Baillieres Best Pract Res Clin Haematol. 2000;13:151-162.

45. Zaucha JM, Mielcarek M, Takatu A, et al. Engraftment of early erythroid progenitors is not delayed after non-myeloablative major ABO-incompatible haematopoietic stem cell transplantation. $\mathrm{Br} \mathrm{J}$ Haematol. 2002;119:740-750.
46. McSweeney PA, Storb R. Mixed chimerism: preclinical studies and clinical applications. Biol Blood Marrow Transplant. 1999;5:192203.

47. Baron F, Little M-T, Storb R. Kinetics of engraftment following allogeneic hematopoietic cell transplantation with reduced-intensity or nonmyeloablative conditioning. Blood Rev. 2005;19:153-164. 